\title{
Institutional design and conflict: an introduction
}

\author{
Massimo Morelli
}

Published online: 26 March 2009

(C) Springer-Verlag 2009

Among the prevalent objectives that we should set for our society, reduction of conflicts of all kinds is probably one of the easiest to agree upon. Any social contract that establishes peaceful ways to resolve disputes can Pareto-dominate, for some appropriate transfers or side payments, any social contract that instead lets individuals or groups resolve disputes through costly conflict.

Given that the international order is a highly incomplete social contract and given that no authority has enforcement power over sovereign States, renegotiation is unavoidable when considering the international order. Moreover, such negotiations are more likely to become conflictual when the relevant players lack commitment power needed for side payments and/or lack precise information about the strength of the opponents. Since all these critical elements for peaceful negotiations to succeed, namely enforcement power, commitment power, and completeness of information, are most unlikely to exist in the international arena, international relations are the type of relations in which anarchy is most often the reality and conflict is the hardest to avoid.

Yet, even in the most pessimistic world of anarchy, the quest for self enforcing institutions that may help conflict resolution or the reduction of negotiation and renegotiation costs is an important one, and a lot more work can be done by economists and political scientists to identify self-enforcing institutional mechanisms that work better than others and that therefore the relevant players could coordinate on. This issue contains some important contributions in this direction, and it can be viewed as divided in two parts: The first three papers deal with the difficult issues of alliance formation and alliance behavior in negotiations and contests, which is an important

M. Morelli (凶)

Economics Department and Political Science Department,

Columbia University, 720 International Affairs Building, MC 3320,

420 West 118th Street, New York, NY 10027, USA

e-mail: mm3331@columbia.edu 
and realistic departure from atomistic models of bargaining. The second part will instead be focused on institutional design issues that arise even when ignoring the complexities of multilateral interactions and limiting attention to bilateral crises.

The first paper in this issue, "Power and efficiency in pillage games," by Jordan, studies the conditions under which the endogenous balance of power between endogenous alliances in a Hobbesian anarchy can be compatible with an efficient allocation of resources, and clarifies the role of enforcement problems. The distribution of wealth has efficiency effects, so not all distribution of wealths or land have the same output. Output can be redistributed (side payments) even without redistributing wealth, hence with unlimited contract enforcement one would think that society could pick the efficient allocation and then redistribute output to compensate those who have to sacrifice initial control of wealth and make them willing to undertake the pareto improving redistribution of wealth. The problem is that redistributing wealth determines also a redistribution of power, and once power is given up, the initial side payment agreements can be reneged. So the question is under what conditions in an anarchic world one can expect efficient allocations in a stable distribution of power. The results are surprisingly positive if the balance of power is among at least four players. This is interesting for international relations scholars, because typically the comparison between bipolar and multipolar power systems is done by looking at a special type of multipolar system, namely the trilateral system. But Jordan shows that a multipolar distribution of power with only three relevant actors is the least likely to induce efficient allocations. The positive result in the first paper certainly rests, among other things, on an assumption of complete information and perfect coordination of intents within each coalition.

The second paper, "Alliances and negotiations: An incomplete information example" by Manzini and Mariotti, displays the difficulties in negotiations between alliances that can arise when information is not complete and the division of intents within alliances needs to be resolved through some collective decision making institution. The endogenous formation of alliances usually refers to stability notions, and a system of alliances is considered stable, under various definitions of this word, when basically no member of any alliance has incentives to join other alliances who in turn are going to welcome the change. So the notion of alliances is usually associated with the stability of a partition of countries, without specifying much about the internal structure of alliances and about what do they really do with one another. Different internal organizations of an alliance (unanimity rule versus majority rule in bargaining) affect the division of surplus from any bargaining process with external members. Unanimity rule is shown to have an equilibrium that yields the alliance an expected surplus share that is never achievable with majority rule, but even with unanimity rule the possibility of delay and surplus exploitation by the external member cannot be ruled out.

The third paper, "A Model of Strategic Delegation in Contests between Groups", by Brandauer and Englmaier, also studies the importance of the internal structure of coalitions in negotiations. In particular, they study what type of agent different groups delegate for negotiations over contestable resources as a function of the distribution of intensities of preferences within the groups. If the second paper is focusing on the role of different voting rules within alliances when the distribution of intensities is unknown, this paper focuses on the complementary question about the strategic 
delegation of negotiating agents by the median type of each group, hence assuming that each group decides the delegate by majority rule. They find that the equilibrium is almost always asymmetric, with one group choosing an agent more radical than the median and the other vice versa, and that the total amount of resources wasted in contest can be lower with delegation than when the median types themselves of each group determine the amount of resources to be used in the contest.

The second part of the special issue is devoted to institutional design questions for the more studied case of bilateral crises. Rational choice theorists have mostly focused on positive explanations of bargaining breakdowns, in the forms of wars, strikes, or other forms of costly interactions that would not find justification in a world in which transfers are enforceable, commitment to future actions is unproblematic, and information is complete. However, less attention has been given to the more normative use of rational choice, namely the identification of institutional mechanisms that may help more than others to resolve or reduce conflict probabilities or conflict costs.

"Mechanism Design Goes to War: Peaceful Outcomes with Interdependent and Correlated Types," by Fey and Ramsay, reminds us first of all that if the source of inefficient conflict is imperfect information, then it is most likely a problem of imperfect information about the respective probabilities of winning in war for the two countries, since if such probabilities were known and the imperfect information were about the relative costs of conflict then a mechanism to avoid war would always exist, and hence rational agents would have chosen it. When the relevant uncertainty is about relative strength, types are necessarily interdependent, and even the case of negative correlation in the realization of type distribution is relevant. In all these cases there does not exist any mechanism in which the probability of war is always zero and ex post individual rationality constraints hold. Only if the relevant individual rationality constraints are interim (expected settlement better than expected payoff from war) peaceful mechanisms exist, all invoking the use of an active mechanism designer that threatens sanctions.

Sanctions are more directly involved in the paper "Sanctions as Revelation Regimes," by Verdier. In that case the sanctioner is not a third party but instead one of the parties involved. Stronger countries or alliances can try to obtain compliance by recalcitrant countries either by incentives or by sanctions and threats, or both, and this paper shows what circumstances are likely to lead to the different types of sanctioners' behavior, and provides some fitting international relations examples.

The last paper in the issue, "Arbitration Systems and Negotiations," by Adamuz and Ponsati, extends the work of Comte and Jehielle (2004) on arbitration, adding potentially interesting institutional details: an arbitrator can be called to end the negotiation between two players by one player unilaterally, but in other contexts the unanimous agreement of both players is necessary to make an arbitration binding; moreover, in some cases the arbitrator is required to take into account all the previous concessions in the bargaining process (pragmatic arbitrator) while one could consider the institutional alternative in which the arbitrator, once called to decide, can ignore all previous concessions, if any.

In the international relations context third parties rarely have the enforcement power to act as arbitrators and make a definitive decision, since countries are sovereign and can always decide not to obey to the decisions of an arbitrator. However, to the extent 
that such enforcement power exists, it is indeed interesting to ask whether third parties should consider prior concessions or not and whether they should derive power from unanimous agreement to invoke them or not. Similar questions should be asked in future research about third parties acting as mediators in the absence of enforcement power.

It would of course be nice if in the future the study of coalitional stability, multilateral bargaining and contests, and endogenous formation of self enforcing institutions could be integrated in a unified dynamic framework. This goal may be beyond reach, but works like those in this issue are certainly useful building blocks, and I hope they will serve as stimuli for the mechanism design community of scholars to shift more energy and efforts in the area of conflict resolution and maximization of peace. 